\title{
The role of extended weekends in sickness absenteeism
}

\author{
J Vahtera, M Kivimäki, J Pentti
}

\begin{abstract}
Objectives-Employees are thought to lengthen their weekends by voluntary absenteeism, but the magnitude of such potentially reversible behaviour is not known.

Methods-A follow up study based on employers' registers on the dates of work contracts and absences in 27541 permanent full time municipal employees in five towns during 1993-7. The absence rate on each weekday separately for all sick leaves and for $\mathbf{1}$ day sick leaves was determined. Results-3.4\% of the male employees and $5.0 \%$ of the female employees were on sick leave daily. The mean rate of sickness absence was lowest on Mondays, after which it increased towards Wednesday, and remained on the same level for the rest of the week. This pattern applied to both sexes, to each year of the follow up, and across towns, age groups, and income groups. For 1 day sick leaves, representing $4.5 \%$ of the total sickness absenteeism, the rates of sick leave for Mondays and Fridays were 1.4 and 1.9 times greater than those for other weekdays. However, these excess rates account for less than $1 \%$ of all days lost due to sickness absenteeism. Extended weekend absences were more common in men, in young employees, and in those in a low socioeconomic position, and they varied between towns.

Conclusion-Extended weekends seem to contribute only marginally to the days lost due to sickness absenteeism.

(Occup Environ Med 2001;58:818-822)
\end{abstract}

Finnish Institute of

Keywords: occupational health; sickness absence; management

Occupational Health

Hämeenkatu 10,

FIN-20500 Turku,

Finland, and Finnish

Institute of

Occupational Health,

Helsinki, Finland

J Vahtera

M Kivimäki

J Pentti

University of Helsinki, Department of Psychology, Division of Applied Psychology, Helsinki, Finland M Kivimäki

Correspondence to: Dr J Vahtera

jussi.vahtera@occuphealth.fi

Accepted 4 July 2001

Sickness absence is important not only as an indicator of ill health but also as a measure of the use of health services and as a cause of lost productivity. ${ }^{1}$ The Confederation of British Industry noted that in 1996 sickness absence represented about $3.7 \%$ of the total working time. ${ }^{2}$ In the United States, the total days lost due to sickness absence were estimated to represent $3 \%-7 \%$ of the regularly scheduled work days, ${ }^{3-5}$ signifying a loss of about 550 million work days each year for the industry. ${ }^{6}$ These figures are compatible with those in other western countries. ${ }^{78}$

It has been suggested that employees tend to extend their weekends by voluntary absenteeism, a phenomenon known as blue Monday absence, recuperation absence, or extended

\section{Main messages}

- Employees are assumed to extend their weekends by voluntary absenteeism, but it has not been known to what extent the total number of sickness absences is attributable to such potentially reversible behaviour.

- The rate of all sick leaves was lowest for Mondays, and there was no variation in the rates of sick leave between Wednesday and Friday.

- In 1 day absences, the rate of sick leave for Mondays and Fridays was higher than that for other weekdays, but extended weekend absences accounted for only $0.6 \%-0.9 \%$ of all days lost due to sickness absenteeism.

- Periods of illnesses lasting 2 or 3 days and occurring over the weekend, either beginning on Fridays or ending on Mondays, may overestimate the figures found for extended weekend absences.

Policy implications

- Sickness absenteeism will probably continue to be a significant problem in industrialised countries in the foreseeable future.

- From the managerial point of view, the key issue is the proportion of absenteeism that is avoidable.

- Organisational policies aiming to reduce Monday and Friday absences may not be an effective way of reducing absenteeism. weekend absence. ${ }^{9-11}$ However, it is still not known to what extent the total number of sickness absences are attributable to such potentially reversible behaviour. ${ }^{12}$ Empirical studies on extended weekend absenteeism are based on relatively small samples and short follow up periods. The findings are controversial. Some studies underline the problem and report increased rates of sick leaves-for example, at the time of shift changes among shift workers and after Sunday in day workers, ${ }^{11-13}$ but other investigations do not support daily variation in absences or moods. ${ }^{14}{ }^{15}$ In terms of managing absences, reliable information on the magnitude of extra Friday and Monday absences would be helpful. ${ }^{8}$ Thus, we used large register data on municipal employees to study this question. 


\section{Methods}

Data were drawn from the ongoing Finnish 10 town study, which is a cohort study exploring the relations between psychosocial factors and health. We selected all the five towns (Turku, Vantaa, Oulu, Raisio, and Naantali) in which the employers' computer stored records covered the 5 year period from 1 January 1993 to 31 December 1997. The participants were 27541 permanent municipal employees, the total full time staff in the service of these towns. We obtained records for all periods on dates of start and, where appropriate, end of work contracts; sex; age; occupational titles; and dates on which each period of absence began and ended with the reasons stated. In men, 58\% worked in non-manual occupations and $42 \%$ in manual occupations. The corresponding figures for women were $72 \%$ and $28 \%$, respectively. Approval of the ethics committee of the Finnish Institute of Occupational Health was obtained for the study.

As in our earlier studies, ${ }^{16}{ }^{17}$ we calculated the number of days during which sick leaves could take place by subtracting the number of days off work for reasons other than sickness or trauma, from the total possible working days. There was 95586 person-years between 1 January 1993 and 31 December 1997. We calculated the number of days expected to be worked for each day of the week. This gave 4978656 Mondays, 4972755 Tuesdays, 4973022 Wednesdays, 4954499 Thursdays, and 4970742 Fridays.

From the records on absences, we drew out all the periods coded as sick leave or trauma. The employers participating in the 10 town study record each sick leave period of every employee, including the dates when each spell starts and ends. In accordance with the regulations, each sick leave certificate must be forwarded for recording. In the towns studied, the employees are paid a full salary during their sick leaves from the first day. The employees can complete their own forms on sick leaves of up to 3 days. For sick leaves of over 3 days, a medical certificate is always required. Municipal employers receive compensation for loss of salary due to sick leaves longer than 10 days from the Finnish Social Insurance Institution. To receive the full compensation to which the employers are entitled, they are motivated to keep strict records of sick leaves. Absences due to caring for a sick child are not included in the sickness absences. Regulations about the work contracts made by Finnish municipalities allow an employee to be absent from work without interruptions in salary payment to care for his or her under 10 year old child with an acute illness. Each such absence spell is fully compensated up to 3 days, and there are no limitations in the number of the spells/employee/year. Thus, the participants had no reason to wrongly report being ill when staying at home to care for their own sick child.

All sick leaves from 1 January 1993 to 31 December 1997 were noted, and the records were checked for inconsistencies. Overlapping or consecutive spells of sickness absence were combined. For each day of the week, we determined the number of days lost due to sick leave, irrespective of duration and due to 1 day sick leaves. There were 205424 Mondays, 224745 Tuesdays, 235223 Wednesdays, 235819 Thursdays, and 236029 Fridays lost due to illness, resulting in a total of 1.137 million days off work between Monday and Friday due to sickness absence. Of these, 50831 were 1 day sick leaves. Only $2.7 \%$ of all 1 day sick leaves occurred on Saturday or Sunday indicating that weekend work was a rare exception in our sample.

We investigated the magnitude of daily variation in sick leaves irrespective of their duration, and separately in the case of 1 day sick leaves. We studied whether this variation was dependent on town, year, or demographic characteristics of the employees. The towns were located in different parts of Finland and their size varied from 13000 to 171000 inhabitants. The study period covered both a deep economic recession (1993-4) and a strong boom in Finland (1996-7). ${ }^{18}$ The demographic factors studied were sex, age (18-29 years; 30-39; years; 40-49 years; and 50-65 years) and monthly income as a measure of socioeconomic status (less than FIM 8000; FIM 8000-10 999; FIM 11 000-13 999; FIM 14 000-16 999; and over FIM 17 000). Occupational titles, expressed in five digit Statistics Finland (official Finnish government statistics) codes were used to link information on income to the data set. ${ }^{19}$ The average monthly income figures, separately for men and women by the 1436 occupational titles, were derived from Statistics Finland. There are only small differences in annual incomes for each occupation between the towns because the conditions for municipal workers are agreed on nationally in Finland.

Poisson regression analysis was used to model the distribution of the number of employees on sick leave in a multiway contingency table. ${ }^{2021}$ Cell counts were classified by six factors: weekday, sex, town, year, age group, and income group. For each weekday, we determined absence rates of all sick leaves and 1 day sick leaves/100 days. Rate ratios and their $95 \%$ confidence intervals (95\% CIs) of Mondays and Fridays compared with the mean rate between Tuesday and Thursday were calculated. For 1 day sick leaves, the dispersion was as predicted by the Poisson model. However, the dispersion of all sick leaves was greater than that predicted by the Poisson model, and we used the square root of deviance divided by degrees of freedom to adjust for standard errors. This had no effect on the rate ratio estimates, but the widths of the $95 \%$ CIs increased. We determined whether the rate ratios depended on demographics, town, or year by testing the interactions between each variable and weekday on absence rate. ${ }^{22}$ Age, sex, and income were adjusted in the analyses. However, because the distribution of demographics did not vary between weekdays this had little effect on the figures. The analyses were performed using the GENMOD procedure in the SAS program. ${ }^{23}$ 
Table 1 Days worked and absence rates by place, time, age, and socioeconomic status

\begin{tabular}{|c|c|c|c|c|c|c|}
\hline & \multirow[b]{2}{*}{ Person-years } & \multicolumn{5}{|c|}{ Absence rate/100 days* } \\
\hline & & Monday & Tuesday & Wednesday & Thursday & Friday \\
\hline \multicolumn{7}{|l|}{ Municipality: $\dagger$} \\
\hline Raisio & 4511 & 3.44 & 3.70 & 3.81 & 3.79 & 3.77 \\
\hline Naantali & 2526 & 3.47 & 3.72 & 3.78 & 3.80 & 3.81 \\
\hline Turku & 35684 & 4.57 & 4.97 & 5.18 & 5.23 & 5.25 \\
\hline Vantaa & 28974 & 3.51 & 3.90 & 4.11 & 4.12 & 4.07 \\
\hline Oulu & 23892 & 4.40 & 4.84 & 5.08 & 5.12 & 5.11 \\
\hline \multicolumn{7}{|l|}{ Year: $\dagger$} \\
\hline 1993 & 18702 & 3.85 & 4.27 & 4.47 & 4.49 & 4.43 \\
\hline 1994 & 19014 & 3.98 & 4.31 & 4.52 & 4.52 & 4.56 \\
\hline 1995 & 18869 & 4.28 & 4.68 & 4.91 & 4.98 & 4.96 \\
\hline 1996 & 19267 & 4.21 & 4.62 & 4.85 & 4.87 & 4.85 \\
\hline 1997 & 19734 & 4.30 & 4.70 & 4.88 & 4.92 & 4.94 \\
\hline \multicolumn{7}{|l|}{ Age $(y): \dagger$} \\
\hline $18-29$ & 5044 & 3.68 & 4.19 & 4.42 & 4.45 & 4.36 \\
\hline $30-39$ & 24087 & 3.51 & 3.93 & 4.13 & 4.14 & 4.12 \\
\hline $40-49$ & 38026 & 3.68 & 4.06 & 4.26 & 4.28 & 4.26 \\
\hline $50-65$ & 28430 & 5.32 & 5.70 & 5.92 & 5.98 & 6.00 \\
\hline \multicolumn{7}{|c|}{ Income (FIM/month): $†$} \\
\hline$<8000$ & 18448 & 6.35 & 6.92 & 7.25 & 7.33 & 7.37 \\
\hline 8000-10999 & 46039 & 4.31 & 4.75 & 4.99 & 5.02 & 5.00 \\
\hline $11000-13999$ & 17155 & 2.86 & 3.12 & 3.23 & 3.25 & 3.22 \\
\hline $14000-16999$ & 10397 & 2.18 & 2.35 & 2.44 & 2.42 & 2.37 \\
\hline$\geqslant 17000$ & 3547 & 2.04 & 2.21 & 2.26 & 2.26 & 2.25 \\
\hline All & 95586 & 4.13 & 4.52 & 4.73 & 4.76 & 4.75 \\
\hline
\end{tabular}

*Adjustment for sex, age, and income did not change these figures.

tp Value for interaction with day of the week on sick leaves NS ( $p$ values $0.52-0.99$ ).

\section{Results}

A total of $3.35 \%$ of the male employees and $4.95 \%$ of the female employees were daily on sick leave. The level of sickness absence varied between towns and there was a clear socioeconomic gradient of sick leaves (table 1). The figures were higher after the recession than during it, and in the oldest age group compared with the others. For both sexes, the mean rate of sickness absence was lowest on Monday (fig 1). After that it increased towards Wednesday, and remained nearly the same during the rest of the week. This general pattern was replicated across towns, in each year, and across age and income groups (table 1).

A different pattern emerged for 1 day sick leaves (fig 1, table 2). The mean percentage of employees off work due to these very short spells was only $0.11 \%$ for men and $0.23 \%$ for women. There was a declining trend in absence rate with increasing age, but no consistent socioeconomic gradient between each category of income and no association with the year. One day sick leaves accumulated around the weekend. The absence rates for Monday and Friday were 1.44 (95\% CI 1.40 to 1.47 ) and 1.87 (1.83 to 1.91 ) times higher than those for other weekdays. The U shaped pattern of daily variation was evident in both sexes, in each municipality, in every year, and in all age and income groups.

The test of interactions showed that the rate ratios for Mondays or Fridays versus other weekdays were dependent on demographics and on the town (table 2). Monday absences were more common among men and younger employees than among women and older employees. Monday absences were less common in Oulu than in the other towns. Friday absences were usual among low income employees.

We wanted to study the possibility that periods of illness lasting 2 or 3 days, either beginning on Fridays or ending on Mondays,
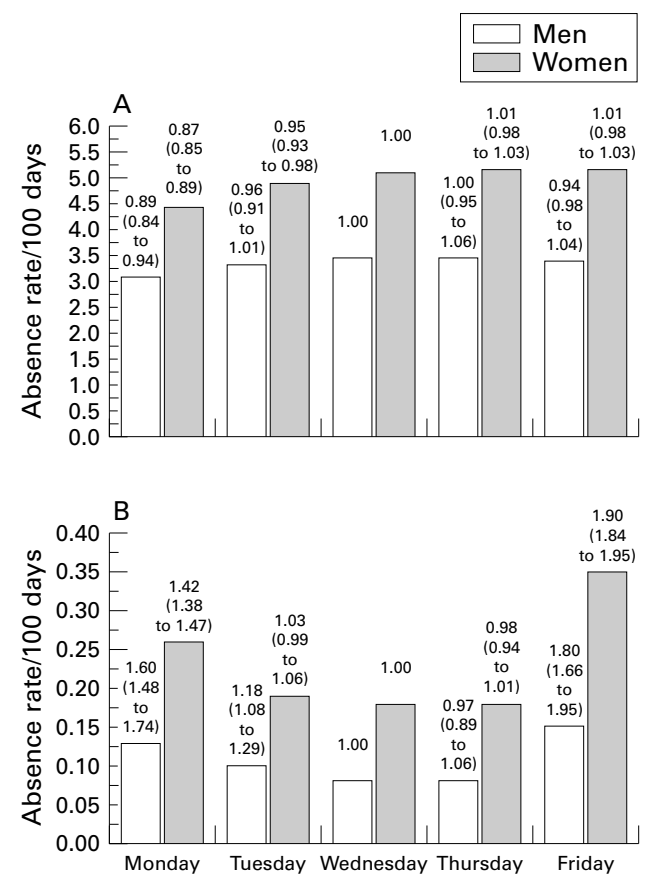

Figure 1 Absence rates and rate ratios (95\% CIs) of $(A)$ all sick leaves and (B) 1 day sick leaves. Follow up time was 22075 person-years for men and 73511 person years for women. $p$ Value for interaction between sex and weekday on all sick leaves 0.40 and on 1 day sick leaves $<0.001$.

might bias the figures for 1 day absences on Mondays and Fridays. To do this, we determined the number of 2 day and 3 day absences which began or ended on each weekday. For Monday and Thursday, the proportion of 1 to 3 day sick leaves was determined by their ending; for Tuesday and Friday, the respective figures were determined by their beginning (table 3). The percentages of 2 and 3 day sick leaves ending on Monday or beginning on Friday varied between $8 \%$ and $14 \%$. For Tuesday and Thursday, the corresponding percentage was $62 \%$. This implies that up to $48 \%-54 \%$ of the illnesses causing a 1 day sick leave on Monday 
Table 2 Absence rates and rate ratios of 1 day sick leave by place, time, age, and socioeconomic status

\begin{tabular}{|c|c|c|c|c|c|c|c|c|}
\hline & \multicolumn{5}{|c|}{ Absence rate/100 days* } & \multicolumn{2}{|l|}{ Rate ratiof $(95 \%$ CI) } & \multirow{2}{*}{$\begin{array}{l}p \text { Value for } \\
\text { interaction }\end{array}$} \\
\hline & Monday & Tuesday & Wednesday & Thursday & Friday & Monday & Friday & \\
\hline Municipality: & & & & & & & & $<0.001$ \\
\hline Raisio & 0.21 & 0.15 & 0.13 & 0.12 & 0.23 & $1.58(1.42$ to 1.76$)$ & $1.69(1.52$ to 1.88$)$ & \\
\hline Naantali & 0.14 & 0.09 & 0.09 & 0.09 & 0.19 & 1.61 (1.35 to 1.92$)$ & 2.08 (1.77 to 2.45$)$ & \\
\hline Turku & 0.24 & 0.18 & 0.17 & 0.16 & 0.33 & $1.41(1.36$ to 1.46$)$ & 1.95 (1.89 to 2.02$)$ & \\
\hline Vantaa & 0.29 & 0.20 & 0.19 & 0.19 & 0.35 & $1.51(1.45$ to 1.56$)$ & $1.83(1.77$ to 1.89$)$ & \\
\hline Oulu & 0.17 & 0.14 & 0.13 & 0.12 & 0.23 & $1.32(1.26$ to 1.39$)$ & 1.81 (1.73 to 1.89$)$ & \\
\hline Year: & & & & & & & & 0.477 \\
\hline 1993 & 0.23 & 0.18 & 0.16 & 0.16 & 0.31 & $1.39(1.33$ to 1.47$)$ & $1.84(1.76$ to 1.92$)$ & \\
\hline 1994 & 0.23 & 0.16 & 0.16 & 0.15 & 0.30 & $1.44(1.37$ to 1.52$)$ & $1.90(1.81$ to 1.99$)$ & \\
\hline 1995 & 0.23 & 0.16 & 0.16 & 0.16 & 0.31 & $1.43(1.36$ to 1.51$)$ & $1.94(1.85$ to 2.03$)$ & \\
\hline 1996 & 0.24 & 0.18 & 0.16 & 0.16 & 0.31 & $1.47(1.40$ to 1.54$)$ & $1.88(1.80$ to 1.96$)$ & \\
\hline 1997 & 0.24 & 0.17 & 0.17 & 0.15 & 0.30 & $1.44(1.37$ to 1.51$)$ & $1.81(1.73$ to 1.90$)$ & \\
\hline Age $(y)$ : & & & & & & & & 0.007 \\
\hline $18-29$ & 0.37 & 0.26 & 0.23 & 0.26 & 0.45 & $1.48(1.37$ to 1.60$)$ & $1.82(1.69$ to 1.95$)$ & \\
\hline $30-39$ & 0.30 & 0.21 & 0.20 & 0.20 & 0.39 & $1.49(1.43$ to 1.55$)$ & $1.89(1.82$ to 1.96$)$ & \\
\hline $40-49$ & 0.22 & 0.15 & 0.15 & 0.14 & 0.28 & $1.45(1.40$ to 1.51$)$ & $1.88(1.82$ to 1.95$)$ & \\
\hline $50-65$ & 0.17 & 0.14 & 0.13 & 0.12 & 0.24 & $1.32(1.26$ to 1.39$)$ & $1.85(1.77$ to 1.93$)$ & \\
\hline Income (FIM/month): & & & & & & & & $<0.001$ \\
\hline$<8000$ & 0.23 & 0.17 & 0.16 & 0.15 & 0.34 & 1.41 (1.34 to 1.49$)$ & $2.16(2.06$ to 2.26$)$ & \\
\hline 8000-10999 & 0.27 & 0.20 & 0.19 & 0.19 & 0.36 & $1.39(1.35$ to 1.43$)$ & $1.86(1.81$ to 1.91$)$ & \\
\hline $11000-13999$ & 0.20 & 0.13 & 0.12 & 0.12 & 0.22 & $1.59(1.50$ to 1.68$)$ & 1.77 (1.67 to 1.87$)$ & \\
\hline $14000-16999$ & 0.17 & 0.11 & 0.10 & 0.10 & 0.15 & $1.60(1.48$ to 1.74$)$ & $1.46(1.34$ to 1.59$)$ & \\
\hline$\geqslant 17000$ & 0.15 & 0.11 & 0.10 & 0.09 & 0.16 & $1.43(1.24$ to 1.66$)$ & $1.60(1.39$ to 1.84$)$ & \\
\hline All & 0.23 & 0.17 & 0.16 & 0.16 & 0.30 & $1.44(1.40$ to 1.47$)$ & $1.87(1.83$ to 1.91$)$ & - \\
\hline
\end{tabular}

${ }^{\star}$ Adjustment for sex, age, and income did not change these figures.

tAbsence rate compared with the mean rate of 1 day sick leaves between Tuesday and Thursday.

Table 3 Daily number (\%) of 1-3 day sick leaves by their beginning or ending days

\begin{tabular}{lcccc}
\hline Duration of sick leave (days) & Monday* & Tuesdayt & Thursday* & \multicolumn{1}{c}{ Fridayt } \\
\hline 1 & $11901(92)$ & $8664(38)$ & $8042(38)$ & $15607(86)$ \\
2 & $569(4)$ & $8211(36)$ & $6944(33)$ & $993(7)$ \\
3 & $435(3)$ & $5943(26)$ & $5943(28)$ & $1452(8)$ \\
All 1-3 day sick leaves & 12905 & 22818 & 20929 & 18052 \\
\hline
\end{tabular}

« Last day of a sick leave.

†First day of a sick leave.

for other weekdays. Extended weekend absences were associated with male sex, younger age, low income, and town. These findings may relate, for example, to more prevalent heavy drinking during weekends among the men, young employees, and those in lower socioeconomic positions, ${ }^{25}$ as well as differences in absenteeism cultures. ${ }^{26}{ }^{27}$ Whether self certification affected 1 day absence rates particularly over the weekend may also be questioned. If employees feel like taking a Friday or a Monday off, they might report their sickness as having occurred over the weekend, thus making their absence more believable. However, our results do not support this explanation. Self certified 3 day sick leaves seldom held weekends, and the number of all 1-3 day sick leaves beginning on Fridays was 20\% lower than of those beginning on Tuesday to Thursday.

To put the problem of extended weekend absenteeism in perspective, the figures should be evaluated against all sickness absences. In the present study, extended weekend absences accounted for only $0.6 \%-0.9 \%$ of all days lost due to sickness absenteeism. Even these low figures may be an overestimation. It is possible that periods of illnesses lasting 2 or 3 days, either beginning on Fridays or ending on Mondays, might bias the figures for 1 day absences on Mondays and Fridays by $50 \%$ (a bias not likely in relation to other weekdays). This implies that the extended weekend absences may, in fact, be a rare exception; most employees are more likely to come to work on Friday, after which they can rest for the next 2 days, and come to work again on Monday, after having rested.

Our results were based on an extensive and detailed register data which covered hundreds of different occupations, from manual work to top level non-manual work. As the employees could fill in the forms for their 1 day sick leaves themselves, and receive full compensation from 
the first day, it is likely that practically all "blue Mondays" were captured in the data set. Also, the percentages of employees on sick leave during a workday correspond well with figures presented elsewhere, ${ }^{24}$ as do the findings related to the socioeconomic status health gradient and the association of sex and age with absence rate. ${ }^{13}{ }^{28}$ Higher age increased the risk of overall sickness absences but decreased that of 1 day absences. Compared with employees with high socioeconomic status, those in low socioeconomic status had 3.1-3.3 times higher rates in all sickness absences compared with only 1.5-2.0 times higher rates in 1 day absences. Because higher age and low socioeconomic status are well known predictors of morbidity and mortality, ${ }^{29}$ short sickness spells may not be a reliable measure of health. As in earlier studies, factors related to time as well as locality were associated with sickness absence. ${ }^{16} 2730$ During times such as a deep economic recession, high levels of perceived job insecurity may prevent sickness absence simply because people are afraid to take sick leave. From a broader sociocultural perspective, sickness absence may be seen as a field or a set of fields for the construction of sickness absence practices that are deeply rooted in the history and way of life of the region. ${ }^{27}$

Sickness absence will probably continue to be a significant problem in industrialised countries in the foreseeable future. From the managerial point of view, the key issue is the proportion of absenteeism which is avoidable. Although we found some evidence for the extended weekend absences - that is, absences which are probably not related to sickness, the proportion of days lost was marginal. If this is the case, there is little need for organisational policies aiming to reduce Monday and Friday absences.

We thank $\mathrm{Mr}$ Seppo Antikainen from the University of Tampere, Finland for his help in collecting the data. This study was supported by the Finnish Work Environment Foundation, the Academy of Finland (project 44968), Finnish Occupational Safety and Health Administration, The Finnish Local Government Pensions Institution, and the participating towns.

1 Marmot M, Feeney A, Shipley M, et al. Sickness absence as a measure of health status and functioning: from the UK Whitehall II study. $\mathcal{f}$ Epidemiol Community Health 1995;49:124-30.
2 Confederation of British Industry. Absence and labour turnover survey. London: CBI Publications, 1997.

3 Leigh JP. Correlates of absence from work due to illness. Human Relations 1986;39:81-100.

4 Dalton DR, Mech DJ. On the extent and reduction of avoidable absenteeism: an assessment of absence policy provisions. F Appl Psychol 1991;76:810-17.

5 Johns G. How often were you absent? a review of the use of self reported absence data. 7 Appl Psychol 1994;79:574-91.

6 Elkin AJ, Rosh P. Promoting mental health at the workplace. State of art review. Occup Med 1990;5:739-54

7 Sigman A. The state of corporate health care. Personnel Management 1992; February:24-31.
Manan A. The state of corporate

8 Whitaker SC. The management of sickness absence. Occup Environ Med 2001;58:420-4.

9 Chadwick-Jones JK, Brown CA, Nicholson N. Absence from work: its meaning, measurement, and control. Int Rev Appl Psychol 1973;22:137-55.

10 Muchinsky PM. Employee absenteeism: a review of the literature. F Voc Behav 1977;10:316-40.

11 Eisenberger R. Blue Monday: the loss of the work ethic in America. New York: Paragon House, 1989.

12 Harrison DA, Martocchio JJ. Time for absenteeism: a 20 year review of origins, offshoots, and outcomes. $\mathcal{F}$ Manageyear review of origins,

13 Luz J, Green MS. Sickness absenteeism form work: a critical review of the literature. Public Health Rev 1997;25:89122.

14 Stone AA, Hedges SM, Neale JM, et al. Prospective and cross sectional mood reports no evidence of a "blue Monday" phenomenon. F Pers Soc Psychol 1985;49:129-34.

15 Chadwick-Jones JK, Brown CA, Nicholson N, et al. Absence measures: their reliability and stability in an industrial setting. Personnel Psychol 1971;24:463-70.

16 Vahtera J, Kivimäki M, Pentti J. Effect of organisational downsizing on health of employees. Lancet 1997;350:11248 .

17 Kivimäki M, Vahtera J, Pentti J, et al. Factors underlying the effect of organisational downsizing on health of employees: ongitudinal cohort study. BMF 2000;320:971-5.

18 Statistical yearbook of Finland 1998. Helsinki: Statistics Finland, 1998.

19 Classification of occupations, handbook no 14. Helsinki: Statistics Finland, 1987

20 Aitkin M, Anderson D, Francis B, et al. Statistical modelling in GLIM. Oxford: Oxford Sci Publ, 1989.

21 McCullagh P, Nelder JA. Generalized linear models. London: Chapman and Hall, 1989.

22 Cohen J., Cohen P. Applied multiple regression/correlation analysis for the behavioral sciences. Erlbaum, NJ: Hillsdale, analysis

23 SAS/STAT Software. The genmod procedure, release 6.09. Cary, NC: SAS Institute, 1993. (SAS Technical Report P-243.)

24 Baldamus W, Behrend $\mathrm{H}$. Variations in absenteeism during the week: an index of employee morale. Nature 1950;165: 831-2.

25 Marmot M. Inequality, deprivation and alcohol use. Addiction 1997;92:S13-20.

26 Nicholson N, Johns G. The absence culture and the psychological contract-who's in control of absence? Acad Manage Rev 1985;10:397-407.

27 Virtanen P, Nakari R, Ahonen H, et al. Locality and habitus: the origins of sickness absence practices. Soc Sci Med 2000; the origins

28 North F, Syme SL, Feeney A, et al. Explaining socioeconomic differences in sickness absence: the Whitehall II study. BMF 1993;306:361-6.

29 Mackenbach JP, Kunst AE, Cavelaars AE, et al. Socioeconomic inequalities in morbidity and mortality in western Europe. Lancet 1997;349:1655-9.

30 Virtanen P. An epidemic of "good health" at the work place. Sociol Health Ill 1994;16:394-401.

\section{Rejected manuscripts}

Authors whose submitted articles are rejected will be advised of the decision and one copy of the article, together with any reviewer's comments, will be returned to them. The
Fournal will destroy remaining copies of the article but correspondence and reviewers' comments will be kept. 